when at graduation six of the eight obtain positions as internes in five different hospitals, it is not necessary to advance other arguments. The case is won on its merits.

What is true for this handful would be true for the large army of medical students. A trained and cultured mind creates its own success.

The remaining topics are so closely related that they may be considered together.

I have been paying my attention very freely to the medical colleges of the state, and should be greatly pleased if some one of my professional friends would now retaliate, for the literary institutions of Ohio must be even more vulnerable from a physician's standpoint.

There are universities within the circuit of Ohio where the principles of anatomy, physiology and hygiene form no part of the course of study; others, where the instruction in these branches is of the most elementary character, restricted to a single semester, and to two, or, at the most, three exercises a week. There are other institutions where the instruction, if more satisfactory, is limited to the few students taking special courses. I know of no instance in the state where advanced work in these three branches, or indeed in any one of them, is required of all the students in all the departments.

It is, perhaps, ungracious to criticize the publicschool system. Instruction in the sciences of the human body being here voluntary, or, at the most, of very recent introduction, we should be thankful that it is as good as it is. So far as my observation goes, this instruction is chielly limited to a little memoriter work in osteology. The ability to name and correctly locate the bones of the body is regarded with very great favor, while little or no attention is paid to physiology, and still less, if possible, to hygiene. Important as a knowledge of osteology is in its place, this kind of work bears about the same relation to true instruction that the ability to count up to ten thousand does to an equation of the second degree.

The time has certainly arrived when the principles of personal hygiene and the laws of sanitary science, so far as they have been formulated, should be required factors in our entire educational system. There are to-day probably not less than six thousand young persons in the colleges of the state. Four thousand more are enrolled in the academies, private schools and public institutions. An additional thousand are found in the female colleges and boarding schools. Thus fully eleven thousand of our citizens, mostly between the ages of 55 and $\mathbf{2 2}$, are enjoying the advantages of higher education.

There is not a city nor a village, probably not a township, in the state without representatives in this educational army. To-day they are pupils-tomorrow they take their places in society, and wield an influence proportionate to their fitness for the duties of life. There never was, in the entire history of the state, an association of men with a more profound duty resting upon them than devolves upon this association to-day-to so awaken public attention and public thought as to secure wholesome instruction in personal and community hygiene at these hundreds tof institutions of learning. Nor does our responsisility end here. There are this very day over five hundred thousand children in the public schools of the state; another quarter of a million have at least a quasi-connection with the system. One-seventh, or, if you count the irregular attendance, one-fifth, of the population of the state is obtaining instruction at public expense.

We (the people) have a right to demand that this instruction shall take such channels and embrace such subjects as shall best subserve public interests. We make no unwarranted claim when we assert that if proper instruction in physiology and in the laws of their own being could be given to the young people of this state, there would be, on the one hand, fewer crimes against sex; on the other, purer homes and nobler lives. If the laws of heredity were as clearly understood in the school and in the family as on the farm, our asylums would have fewer inmates, and insanity would not be increasing as to day. "We live in an age," says a recent writer, "when sanitary science is doing much to effect the preservation of the human race ;" but how much more, if its formulated principles could be scattered like autumn leaves upon every man's door-sill.

All this and more, I take it, is the work before this association-all this and more, the work before every educated man and lover of his race. It is a work in which all good citizens of our commonwealth can join hands. There is room then for that spirit of union and co-operation for which I have been pleading. Let us elevate and ennoble education, both general and professional. Let us secure the highest talent and highest preparation for the future devotees of medicine. Let us see to it that our universities, academies and public schools graduate into society young men and young women fitted for the duties which God and the commonwealth impose upon them. Let us spread the laws of sound health and honest living into the most degraded homes of the state, and there will come to this association a charter stronger than if granted by kings, or presidents, or governors - the charter of an approving conscience.

\section{THE LEGAL CONTROL OF MEDICAL PRAC- TICE BY A STATE EXAMINATION.}

BY JOHN B. ROBERTS, M.D.,

PROFESSOR OOF ANATOMY AND SURGERY IN THE PHILADELPHIA POLYCLINIC.

Read at the Fourth Stated Meeting of the Medical Jurisprudence Society, October $r_{3}, 188_{4}$.

It is my intention this evening to briefly review the advantages that would accrue to the public and the medical profession by the enactment of a law placing the control of medical practice in the hands of a state board of examiners. As is known to many of you, a person who desires to practice medicine in Germany must pass a governmental examination. The students study in universities, and take degrees, but such degrees do not confer the right to enter upon practice. The health antl lives of the citizens of the empire are believed too valuable to be imper- 
iled by the acts of ignorant physicians. Hence, although the universities themselves are under the supervision of the state, the candidate for practice must, in addition to his university examination for a degree, pass a governmental examination for license to follow professional work among the people of his vicinity. $\mathrm{He}$ is not a legally qualified practitioner until this is accomplished.

The recklessness with which medical legislation has been neglected in this state will be apparent when I say that the medical schools are under no state or federal supervision whatever. They have entire control of the time and character of studies required from the intending practitioner, examine him upon the same, and confer the medical degree, which is at once accepted by the authorities as evidence of sufficient knowledge and skill to entitle the possessor to practice medicine, surgery and obstetrics in the community. Still further, to encourage wholesale and unrestrained manufacture of physicians, the "doctor manufactories" are, I believe, even exempt from taxation.

Until the year I 88I, there existed in this commonwealth no law whatever regulating medical practice. At that time the law to provide for the registration of all practitioners of medicine and surgery was enacted by the general assembly of Pennsylvania. It effected much good, and was a distinct step forward, though it has, among other minor defects, the weakness that the possession of a genuine diploma is taken as evidence of knowledge.

As long as the medical schools of the United States are dependent for prosperity upon the number of fees received from pupils, and as long as examinations by the faculties who receive these fees are the sole test of skill, a diploma, even from the highest grade institution, carries with it little value as a diagnostic proof of professional learning. The old Latin proverb has it: "Caveat emptor," "Let the buyer beware." I say, "Caveat æger," "Let the sick man beware," if he believes that the fact of graduation from a renowned college confers intelligence and skill. The placard, "No reasonable offer declined," usually tells the buyer that inferior quality of goods is to be expected. Would that many colleges had the honesty to display a similar escutcheon over their portals, reading, " No reasonable ignorance rejected."

The step I advocate tonight is the creation of a board of medical examiners, under state jurisdiction, which shall examine all persons desiring to enter upon practice in this state, after January I, 1886 , without regard to when, where or how they obtained medical education. If such an examination by non-interested persons shows the proper qualifications, the candidate is to be furnished with a certificate, and is then registered in the Prothonotary's office as heretofore. Let the medical schools teach, examine and grant degrees as at present; but let no one practice in this state who has not been examined by those who have no interest in passing or rejecting him. In other words, merely substitute for the diploma the certificate of the State Examining Board as the requisite of registration.

The greatest advantage derived from such a law would be the protection of the public health from ignorant physicians. Bear in mind that I refer now, not to Indian medicine men, negro herb doctors and other charlatans, but to ignorant physicians, graduates of recognized and reputable schools of the United States and other countries; such as are duly armed with beautifuliy engraved diplomas signed by leaders of the profession, and, therefore, more dangerous to the community than a whole tribe of Indian "pow-wow-ers."

The United States government long ago adopted a similar plan of examining candidates for its army and navy medical services; so that at the present time its soldiers and sailors, ever in distant territories and seas, have an average benefit of better-educated physicians than citizens of New York, Philadelphia or Boston. An army or navy surgeon receives his education in any school, but he enters the federal service only after an examination by a board who had nothing to do with teaching him, and who have no pecuniary interest in passing ignorant candidates.

A second advantage of the plan advocated is the improvement in registration that would take place. By the present law, persons who were in continuous practice for ten years prior to its enactment were allowed to register without diploma and without examination. Such persons, if any still reside in the state unregistered, or if any new ones come into the state, would, by the new law, be required to show their qualifications for practice by examination. This would be a gain, as it would exclude a certain proportion of uneducated persons.

Section four of the registration law requires persons coming into this state with diplomas from other countries or states, "to lay the same before the faculty of one of the medical colleges or universities of this commonwealth for inspection, and the faculty, being satisfied as to the qualifications of the applicant and the genuineness of the diploma, shall direct the dean of the faculty to endorse the same, after which such person shall be allowed to register." This imposes a considerable amount of work upon the medical schools, who, doubtless, would gladly be excused from this unpaid and uncongenial labor, for to reject the diploma or graduate of a neighboring institution lays the school open to unjust criticism. Moreover, the law does not state that the said colleges should be schools for undergraduates. Some months ago application was made to me, as Secretary of the Philadelphia Polyclinic and College for Graduates in Medicine, for certification of a man's qualifications for registration under this act. Undoubtedly, post-graduate medical schools were not intended by the law, and I declined to act in the matter. Moreover, there are loopholes in the registration law by which punishment for practicing illegally can be escaped. A notable case occurred six or seven months ago in Clearfield county, and is mentioned in an editorial published in the Polyclinic for March, I 884 .

An exceedingly important result of the establishment of a state examining board in Pennsylvania would be the elevation of the standard of education in the medical colleges of the country. Many citi- 
zens and prospective citizens of the Keystone State study in the colleges of New York, Maryland, Ohio, Michigan and other states. As soon as it is known that no one can practice in this wealthy commonwealth unless he passes the state examination, such persons will study in the highest grade schools, and in those whose graduates show the smallest percentage of failure before the Pennsylvania Examining Board. Hence, if our schools are the best equipped and supply the best education, men will not pay their money to the teachers, boarding-house keepers, and merchants of other states, but will attend our own schools, and thus increase the business prosperity of Pennsylvania. The competition of low grade colleges, whether in this or neighboring states, would not then tend to paralyze the efforts of institutions of high educational standard. There would be no longer a premium offered for quick graduation after two years' study and a five minutes' oral examination in each of seven branches.

Another indirect advantage would be this: that students could study in several institutions, and thus gain the benefit of hearing the foremost teachers of various schools, instead of being cognizant with the precepts of but one faculty. The former method of study is certainly the most elevating, as it broadens professional knowledge.

The division of labor resulting from examinations being held by a non-teaching board, having committees in different parts of the state, would make it possible to hold written and manipulative, as well as oral examinations, and thus do better justice to candidates than is possible by an oral examination alone. Again, the examinations not being held all at one time of year, would further accommodate intending practitioners and lessen the labor of the examiners. As it is now, the college faculties, with great inconvenience to themselves, and often with injustice to the pupils, hurry through the examinations of several hundred students in a few days. A gentleman, now dead, who was for years a professor in a large medical school, once told me of a case where a man who failed to pass his examination was actually graduated, because of a clerical error that occurred in the hurry of commencement time. Neither of us knew how many people owed their deaths to that accidental physician. Bright men may have been rejected by similar errors made in hasty examinations. The state board examinations would be conducted leisurely, and, being partly written, would show by the records whether a man was unjustly recorded. $\mathrm{He}$ would also have the right to a public appeal from the report of the board, which now he has not. The college examination is, as it should be under the present arrangement, the private business of a private corporation, and therefore sealed from public inspection.

Another advantage which deserves consideration is the power of revoking a man's license to practice, which would be possible if a State Examination Board is instituted. His diploma cannot and could not be taken away, but his certificate of knowledge, character, etc., could be canceled or withdrawn by the board if he was convicted of criminal malpractice or similar crime.
The last reason for advocating the law is cogent; but to my mind deserves little attention, because it is a selfish one, which should influence us much less. than those previously discussed. Such an examination would weed out and keep out of the profession those persons who, though ignorant of medical science, accept professional duties and emoluments, and thus increase the difficulty of an educated physician gaining a livelihood. There are, undoubtedly, too many physicians for the needs of the closely settled districts. Fewer doctors, and better ones, would be a boon to most sections of the state. The state examination would effect both objects. The legal profession has, I believe, certain restrictions to indiscriminate admission to the bar. Why should not the medical profession have some similar protection.

Dr. Isaac Ashe speaks of districts in Scotland where sixpenny charges are made by physicians, and says he knows of an English town of 50,000 inhab. itants where one shilling charges are made for medical advice. ["Medical Politics," the Carmichael Prize Essay for 1873 , p. 33.] He quotes from the Medical Press and Circular, of September I 1,1872 , p. 216 , the following charges adopted by a practitioner of thirty years' experience: "Midwifery, two shillings and sixpence; advice, sixpence; consultations, one shilling." Is there a barrister in England, or an attorney-at-law in Pennsylvania, who accepts such insignificant fees for professional services? Yet the position of the medical profession in Pennsylvania is little better than that mentioned in England. The poor estimate put upon medical service is due to the overcrowded state of the profession and the inferior quality of much medical work, both of which conditions would steadily decrease after the initiation of a state examination.

That the medical profession desires the adoption of a state examining board may be assumed from the recent action of the Philadelphia County Medical Society. At a meeting of the present month, in which this and kindred educational topics were fully discussed by college professors, and practitioners, both general and special, the following resolutions were offered. After postponement for printing and circulation they were adopted :

Resolved, That the Philadelphia County Medical Society believes that the status of the medical profession of this state will be elevated by the establishment of a non-teaching Board of Medical Examiners, whose certificate shall be the only one accepted by the Prothonotary's office for physicians registering after January, 1886.

Resolved, That the other county societies of this state be requested to advocate the establishment of such a board at the next meeting of the State Society, and to discuss the matter, prior to that meeting, with the members of the General Assembly resident in their counties.

Resolved, That the corresponding secretary be directed to transmit a copy of these resolutions to the secretary of each county society, with the request that immediate action be taken, and reported to this society.

Resolved, That a committee be appointed to draft a law creating a State Board of Examiners, for the examination of all persons for license to practice medicine, the said law to be presented at the next meeting of the Medical Society of Pennsylvania by the Philadelphia delegates to that meeting.

Having spoken of the advantageous action of a 
state examining board, I must hastily consider the objections that will be raised to its enactment.

It will be said that physicians living outside of this state, but near its border, are often called to attend patients in Pennsylvania. Very well; let them be examined by the Pennsylvania Board, and register in the county of this state nearest their residences. Shall a physician of New Jersey, Maryland, Delaware, New York or Ohio practice continuously in Pennsylvania, without being subjected to the same examination as residents of this state? Certainly not. Those, however, who come into the state as consultants with duly licensed practitioners of this state should, of course, be excused from the state examination. So should dentists who do not practice medicine, whether residents or non-residents of the state. In the same manner midwives, who attend the very poor in cases of confinement, should be exempt from professional examination, though they undoubtedly should be registered and give some evidence of obstetric knowledge.

A physician changing his residence within the state would merely be required to register in his new locality, but would have to pass no second examination. Nor should those now legally registered and practicing be required to pass the state examination.

It will be urged as an objection that there are physicians who desire to practice special systems of medicine, and that such a state examination would exclude these from practice. Not at all. Let the board examine all candidates on anatomy, physiology, pathology, hygiene, surgery, obstetrics, chemistry and materia medica only, omitting theories of medical practice and therapeutics entirely from the schedule.

I have thus advocated, Mr. President and gentlemen, a measure which will, I believe, add to the wealth and prosperity of the State of Pennsylvania, and elevate the profession of medicine, for whatever elevates the latter must increase the former. The wealth of a community is the health and lives of its citizens. Every useful life saved, every illness shortened, adds to the public treasury. The educated physician may do both; the ignorant physician does neither. I pray you to aid in cultivating the one and eradicating the other.

I II 8 Arch street.

\section{A CASE OF GOITRE WITM OBSTRUCTION--- TRACHEOTOMY---SOME OBSERYATIONS ON TRACHEAL TUBES---EXHIBITION OF PA- TIENT AND MODIFIED TUBES FOB LOW TRACHEOTOMY.}

BY D. W. GRAHAM, A.M., M.D.,

PROFESSOR OF SURGERY, WOMAN'S MEDICAL COLLEGE; SURGEON TO THE CENTRAL DISPENSARY: SURGEON TO THE PRESBYTERIAN HOSPITAL.

Read before the Illinois State Medical Society, May, $r 88_{4}$.

I desire to report this case, both because I think it sufficiently interesting and instructive to put on record as a part of the proceedings of this society, and because it affords a good occasion to present the results of some studies and observations on tracheotomy tubes, which results, I venture to hope, may be of some practical service to the profession.

May Parker, $131 / 2$ years old, in last December first noticed an enlargement of the thyroid gland. She came under my observation for treatment in February following, since which time she has taken pretty large doses of iodine, most of the time in the form of the compound solution. The gland was soft and symmetrically, but not greatly, enlarged-not essentially different from what you now obuerve-although it has diminished somewhat in size since the operation. The isthmus was relatively more enlarged than the lobes, extending from the larynx down to the sternum. During the four weeks of treatment before the operation, the goitre did not apparently increase much in size, but there began to be obstruction to respiration, and marked paroxysmal dyspnœa, chiefly at night. In the early morning of the $24^{\text {th }}$ of March, I was hastily called, and found my patient had barely escaped death in one of these paroxysms. The parents, indeed, supposed at one time that she was dead. I learned that these paroxysms had been gradually increasing in severity for several nights preceding, and that she had not been able to sleep recumbent. The voice was stridulous, and there was decided lividity during the height of the paroxysms. There was decided obstruction to both inspiration and expiration, and the usual sinking in of the soft parts of the thoracic walls on inspiration. I was soon convinced that the patient could not safely pass through another night without relief, and decided upon tracheotomy. Drs. A. B. Strong and J. D. Skeer were called in, and fully concurred in the necessity for the operation. In the hope that the obstruction to respiration was largely due to spasm from pressure or irritation of the laryngeal nerves, and in view of the difficulties that were likely to be met with in the low operation, it was decided first to make an opening above the isthmus. I must give credit to Dr. Skeer, however, by stating here that he did not fully endorse this proceeding. The patient being etherized, I made an opening through the crico-thyroid membrane and the cricoid cartilage, an assistant making traction downward on the upper border of the isthmus, which was in the way. A tube was inserted, but the dyspnœa was not relieved. I immediately proceeded to open the trachea below, and in doing so encountered, in an exaggerated de. gree, a combinution of all the difficulties we are ever liable to meet with in this operation. The trachea recedes from the surface as it passes downward, until at the sternal notch it is nearly an inch and a half (Quain) from the surface, normally in the adult ; but the distance, of course, was increased by the thickened isthmus in this case.

There was absolutely no space for an opening between the sternum and the isthmus, except as the latter was pulled upward out of the way with a blunt hook. On this account, the external wound could not be increased in length to correspond with its depth. There were large turgid veins crowded together and necessarily embarrassing hæmorrhage, and before the operation was completed enough blood entered the trachea to seriously compromise the patient's chances. 